\title{
Integration of Cancer Services in Ontario: \\ The Story of Getting It Done
}

Leslee J. Thompson and Murray T. Martin

Ex-e-cu-tion (ek si kyoo shun) n.

1. The missing link. 2. The main reason organizations fall short of their promises.

3. The gap between what an organization's leaders want to achieve, and the ability of their organizations to deliver it (Bossidy and Charan 2002).

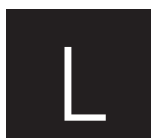

eaders in healthcare have known for years that integrating service delivery makes sense, yet paradoxically across Canada, despite major system restructuring, cancer care has remained the exception. In Ontario it was recognized that this was an area both ripe for and in need of change. The economic impact associated with the growing burden of cancer in Ontario has been well documented (Sullivan et al. 2003). Also well documented are the potential solutions for how cancer services could be better integrated and organized to improve efficiency and quality of care (Hudson 2001). Until recently, however, little action was taken. Traditional biases, turf protection, political minefields and perhaps even restructuring fatigue have been excuses to stand still.
With few exceptions, the majority of Regional Cancer Centres (RCC) run by Cancer Care Ontario (CCO) operated independently from their host hospitals, despite sharing the same patients and being physically linked. CCO was focused almost exclusively on what happened inside the RCCs, and waiting times for radiation therapy became a proxy for how the entire cancer system was working. In reality, however, $70 \%$ of cancer services are provided outside the RCCs, including a large amount of cancer surgery.

Hospitals with and without cancer centres have, for the most part, been left on their own to manage the impact of increased volumes and complexity of cancer care. Cancer patients faced an uneven state of quality and access to the wide variety of essential cancer-related services. CCO, on the other hand, as Ontario's provincial cancer agency, focused almost exclusively on the niche market of radiation therapy.

So what unleashed the ties to this unacceptable status quo? It was a combination of strong leadership, good timing, risk taking and an unwavering focus on the goal of improving quality of care for cancer patients.

January 1, 2004 marked the start of a new era for cancer care in Ontario. Fourteen months after the process of integration really began to take shape, 11 host hospital boards voluntarily signed a Cancer Program Integration Agreement (CPIA) with the board of Cancer Care Ontario. This legally binding 
agreement was, in the words of then Minister of Health and Long Term Care, the Honourable Tony Clement, "a historic achievement." It involved transfers of staff and assets, the establishment of new performance-based funding arrangements and the creation of mechanisms for ongoing planning and improvement of cancer services across province. This article outlines the steps taken by the consortium of leaders who came together and narrowed the gap between wanting to achieve integration and actually delivering on it. It is, in essence, a story about execution: the will and ability to get things done. Lessons learned along the way are included so that our experience might help others.

\section{Creating the Agenda for Action}

Not everyone is given the chance to implement recommendations from reports they author, but shortly after the CSIC Report was submitted, CSIC Chair Alan Hudson was appointed President and CEO of Cancer Care Ontario with precisely that mandate. He arrived at CCO on April 1, 2000, and his first 200 days as leader are described in a previous HQ article. One of his early priorities was to accelerate the integration of RCCs into the host hospitals. As a former hospital CEO, Hudson understood the potential risks and benefits of this change for hospitals. As the former Chair of CSIC, he knew it was necessary to improve the cancer system. He laid the groundwork for change by conducting a province-wide tour.

Meetings were held with all of the future partners: hospital CEOs, board chairs, senior teams and staff within the cancer centres. Meetings were also held with our union leaders to gather views and advice on key transition issues. Important to the change process was that almost everyone agreed that integration would improve patient care. Given this conclusion, discussions moved quickly from whether it should happen, to the conditions under which it should transpire.

Not surprisingly, this open discussion about integration led to speculation about hostile hospital takeovers, job loss and the demise of CCO. Before there could be any productive planning on next steps, the employment status of CCO staff needed to be resolved. Acting swiftly, CCO declared its support of a single employer model at local levels. The CCO staff was told that they would eventually become hospital employees, but there would be no job loss as direct result of integration. It was also decided in early November of 2002 that an all-unions meeting would be held on February 10, 2003 to determine what steps would be taken to facilitate transfers of staff.

Setting the February 10 date was like waving the flag at the start of a race. It was the first of many milestones that were set to ensure that everyone knew that the hospitals and $\mathrm{CCO}$ were serious about proceeding with integration. February 10 also added to the sense of urgency to get our collective acts together, as considerable work had to happen in advance of that meeting.

\section{Coalition Building}

The 11 host hospital CEOs came together as a group with Cancer Care Ontario for the first time in early November 2002. They agreed immediately to steer collectively the integration process and oversee key strategic decisions. From the start, this change was positioned as a joint initiative of $\mathrm{CCO}$ and the regional cancer centre host hospitals, working together to create Integrated Cancer Programs (ICPs) in order to better meet the needs of cancer patients across the province. It was understood, however, that everyone had slightly different motives for coming to the table, and that there were some hospital-specific issues that needed to be addressed up front, before detailed planning could proceed too far.

To this end, another round of consultation was conducted with the help of an outside consultant who had credibility with both CCO and the host hospitals. This consultation fostered robust dialogue among all the key players about the issues we were about to face. A tone of openness, candor and informality was set, and this helped shape the discussions that were yet to come. What became known as the "Ronson Report" was enormously helpful in building a common understanding of what was important to the various players. Intentionally or not, this issue identification approach became fundamental to our combined efforts moving forward.

A tone of mutual trust and teamwork was set at the CEO level, but that group could not carry off the change on their own. Early support and involvement from those that would actually be charged with responsibility to make it happen was essential, and hence teams and task groups were put in place at both local and provincial levels to get the work started. These were not natural teams, and many people from diverse backgrounds and locations were coming together for the first time. Later in the article we will talk about how the structures originally put in place had to change in order to get the work done more effectively.

The February 10 deadline got multiple groups of people focused on the critical issues early on, but it became clear that dedicated resources would be required to support the various teams, pull things together and keep the work on track. To this end, one of the authors of this paper (LJT) was brought on by $\mathrm{CCO}$ with a mandate to drive the integration process to completion. Hospitals, RCCs and the Ministry also identified a few key people that would spend considerable time on this initiative. In fact, the Ministry set up a special committee chaired by an Assistant Deputy that met with CCO on a biweekly basis throughout the integration process. This was very helpful, and sent an important signal inside and outside of the government that the change was important.

Coalition building continued on multiple fronts throughout the process. People invested in the new relationships that were being created, because there were both short- and long-term implications of our work together. 


\section{Deadlines and Deliverables}

The approach of "always begin with the end in mind" was used throughout this process. June 30 was set as target date for completion of a master contract between Cancer Care Ontario and each individual hospital. Working backwards, key milestones and work plans were put in place to achieve the June 30 deadline. The $\mathrm{CEO}$ group agreed to seven key principles to guide the development of the contract. These became touchstones to which we referred, but never changed or revisited, in the days and months that followed.

To provide appropriate assurances to their respective boards, CEOs were unanimous in their view that written confirmation of the Minister's support was required for the creation of ICPs, and for the set of seven principles. Most critical was the principle that one-time and ongoing costs directly associated with integration would be funded, such that the uptake of a new program did not negatively impact the hospitals' budgets. A positive response from the Minister was received on Feb. 7, just in time for our meeting with union leaders across the province. This was the first of a number of important letters from the Ministry over the course of the process that could be quoted widely, to let people know that integration had the Ministry's full support.

It is important to note that there was no directive or mandate requiring hospitals to participate in this effort: it was voluntary. It was the CEOs who decided not only to proceed, but also to proceed together in a collective fashion.

There was much nervousness about the meeting with 56 union leaders from around the province. But thanks to the help and input of many individuals, it went well and was another critical turning point along the change curve. The next big milestone was to get a first draft of the contract out in time for the Contract Summit to be held March 6 with the CEOs and Regional VPs.

The pattern of openly declaring deadlines and deliverables was repeated throughout the change process. Each time we put our credibility on the line, and then hit milestone targets, everyone could join in the celebration of "wins" along the way. This approach helped build momentum and commitment from diverse stakeholder groups to stay on course and take each subsequent step. Work proceeded swiftly, and perfection was not the goal. We tried to be responsive to important issues, but did not seek consensus on everything. This "truth over harmony" philosophy prevailed, enabling us to unearth critical thinking and creative solutions along the way, while preventing us from getting bogged down in process.

Tight timelines helped bring closure on key issues. Open commitments to deliverables ensured that we kept moving forward as planned. We remained focused on the goals, but flexible in our approach to achieving them. Task groups were started up and wound down depending on specific requirements. We learned early on that it was ineffective to create teams with "representatives" from different organizations just for the sake of saying we did. We needed different skills and levels of authority around the table at different times to make decisions and move on. There was a constant finessing of who worked on what and when. In the end, it was a relatively small group that did the lion's share of the work. This approach succeeded because we were committed to an open and transparent process. Information was freely shared, and for the most part well communicated.

\section{We needed different skills \\ and levels of authority around the table at different times to make decisions and move on.}

There were many opportunities for delays and derailments during this period: the SARS crisis, concurrent forensic audits, operational reviews and a looming provincial election. Instead of working against us, however, these dynamics kept us away from details that were not important, and focused us on the more important objectives we had signed on to achieve. People persevered through this difficult period, because the goal was important. In addition, there were enough egos involved to ensure that failure was not an option.

\section{The Agreement}

The purpose of the Cancer Program Integration Agreement (CPIA) is to outline the respective roles and obligations of each hospital and CCO for the creation, evolution and ongoing performance of a single, integrated cancer program (ICP). The ICP brings together inpatient, outpatient and some community-based oncology services, including hub sites of the Ontario Breast Screening Program, under the single leadership of a Regional Vice-President for Cancer Services (RVP). The RVP is responsible to the hospital for the management of the ICP and to $\mathrm{CCO}$ for leading the development of regional cancer programs and participating in provincial leadership activities.

By signing the Agreement, the parties entered into a longterm contractual arrangement designed to improve the quality of cancer care, and to create accountability for performance at both the hospital and system level. The ICP is funded through 
both CCO (for transferred programs) and the hospital (for inpatient and clinical support services), and there are some levels of protection for cancer services built into this arrangement. It is expected that $\mathrm{CCO}$ will advise the Ministry on required growth funding for the entire ICP, as well as for the allocation of funds for cancer services across other areas of the province.

Funding from $\mathrm{CCO}$ is determined in part by the hospital's ability to meet certain performance requirements related to volumes, quality and reporting. Everyone knew that the sophistication related to measurement and reporting of performance requirements would evolve as we worked together over time. This focused us on working out the conditions necessary for effective planning, monitoring and problem-solving related to performance-based funding, rather than on immediately trying to pin down all the right metrics. In terms of quality, we built in joint incentives to improve and reach provincial standards and to allow for publicly reported data comparisons across hospitals.

The Agreement was structured in a way that all parties agreed early on to the philosophy that "everyone signs, or the deal doesn't go through." We pressed hard on each other to keep this approach intact, although there was indeed a point in time when we all wondered if this was the right thing to do. The power of the collective helped to keep things moving forward, but there was always the possibility that any one of the 12 organizations could choose not to go the distance.

There is a single master agreement with CCO dealing with all the substantive issues that are common to all 11 hospitals. Hospital-specific issues were dealt with in a series of attachments. The agreements were signed by the board of CCO and the boards of each individual hospital. There was considerable discussion about whether the Ministry should be a party to the Agreement. In general, the hospital CEOs wanted to see that the Ministry was committed to integration and would support its implementation. In other jurisdictions, hospital performance agreements are typically held directly between the Ministry and hospitals or Regional Health Authorities. In this situation, the role of $\mathrm{CCO}$ as an arm's-length provincial agency of government was unique. CCO played somewhat of a brokering role, balancing the issues, demands and expectations of both the Ministry and our partner hospitals. Because of this, there was a sense that things were a little too CCO-heavy at times. However, everyone was committed to creating lasting partnerships, so healthy adjustments to the process were made.

\section{Negotiations}

Things definitely got more difficult when it came time to tackle the details. The hospitals' decision to use a single law firm to represent their interests turned out to be one of the most critical of all success factors in this story. Both sides wanted the lawyers to co-draft the agreement. This was an unusual, but important step that helped keep a positive tone during the negotiation process. However, even with legal counsel now involved, we were able to sustain the candid and collaborative tone that had been set early on.

There were both collective and individual phases to the negotiation process. First, the CCO-Hospital negotiating team generated the final draft of the Master Agreement over a twoweek period at the beginning of May. This draft was signed off "in principle" via teleconference by the CEO group within three days of its circulation. There were some tough issues for us to resolve, but people kept focused on the big picture, and there was lots of give and take to accommodate the interests and needs of all sides. Once this draft was pinned down, CEOs set out to get their respective boards ready for approvals that were required by the end of June, and the individual phase of negotiations began.

Individual negotiations involved $\mathrm{CCO}$ and each hospital coming to agreement on the terms of 16 schedules that were specific to each hospital. These schedules established budgets, performance indicators and details related to the transfer of staff and assets. Two people from CCO made a whirlwind tour of the province over a two-week period, and negotiations were all successfully concluded on time. Part of the reason for success at this stage was that all the substantial issues had been dealt with during the collective phase, and there was a firm stand that no side deals or reworks of the master agreement would be entertained. Also, knowing that a three-month due diligence process was to follow, some of the pressure to get it all right was reduced. We "parked" a number of issues that needed to be resolved down the road, and kept ourselves focused on those elements that were essential for board-level approvals of the agreement by June 30 .

\section{Closing the Deal}

The boards of Cancer Care Ontario and each of the 11 hospitals approved the integration agreement before our June 30 deadline, subject to a rigorous due diligence process that would take place over the months that were to follow. With all the financial pressures that hospitals were facing at the time, and the increasing scrutiny of board decision-making, this was a tenuous phase of the process. Hospital boards wanted assurance that, notwithstanding all the positive benefits for patients and their communities, the cancer program would not become another "loss leader" for the hospitals to contend with. The CCO board wanted assurance that it was not giving away its ability to ensure quality cancer care by handing over management of the cancer program to the hospitals. The performance-based funding relationship was going to be new for both parties, and there was discomfort in some quarters about moving in this direction. After six months of first-hand experience working together, however, all the CEOs and their senior teams were able to say that, in spite of uncertainties, the partnerships they were entering into were going to benefit everyone, especially patients. 
Closing the deal depended on CCO getting written confirmation from the Minister of Health that he fully supported the terms and conditions of the Agreement, and that key integration costs would be covered. In spite of ongoing assurances that this would be so, hospitals were skeptical, and CCO had to work hard to ensure that there would be no last-minute surprises. But as June 30 drew close - and hospital boards were already starting to sign on expecting this condition to be met - an eleventh-hour turn of events nearly stopped the whole process in its tracks. Then, after some spirited behind-the-scenes activity, a letter arrived with details of the financial deal between $\mathrm{CCO}$ and the Ministry, and this enabled all 11 deals to proceed as planned and on time. There were great sighs of relief, as well as some utterances of disbelief that things had actually come together as well as they did.

Our next hurdle was the due diligence process and preparation for transfers of staff and assets. The July to December period was filled with a great deal of technical legal work and detailed implementation planning. It was agreed that December 31 would be the transfer date, and everyone worked flat out to ensure that our deadline was met. In the end, there was only one hospital board that pushed back in the final days. There was genuine concern that the additional financial risk being assumed was too great for a hospital that was already underfunded. Another flurry of activity ensured that the issues were effectively resolved in the end.

We learned what others already know - it's never over until it's over. And, if you don't pay attention to finishing what you started and soldier on until everything is taken care of, you are at risk of everything coming undone.

\section{THE TRANSFER}

Approximately 3,000 unionized and non-unionized employees working in 11 different locations were transferred from CCO to the hospitals on January 1, 2004. Joint HR principles were established early on in the process, so that as hospitals proceeded to conduct local negotiations with unions, there would be a consistent approach to how employees were treated. Most of the CCO staff was worried that they would be "swallowed up" by the hospital despite assurances to the contrary. Some had to join or change unions. Others moved over to the hospital but there was, as promised, no involuntary job loss as a direct result of integration. The profound cultural differences between some of the cancer centres and the hospitals would take time to accommodate, but transition teams were in place at most of the RCCs to help address staff concerns. Efforts were made to ensure open and honest communication along the way.

The transfer of assets was another important, albeit more technical, part of the change. There was significant involvement from the lawyers on this front. Detailed asset lists, licensing agreements, due-diligence checks and new contracts (among other specifics) all needed to be accounted for and risk-mitigated. The number of details to sort out between the partners in the final weeks was mind-numbing and exhausting. By focusing on the long-term goal, everyone got through this phase.

Ultimately, on January 1, 2004, three central ideas became reality. First, the staff and assets of 11 RCCs were officially transferred from $\mathrm{CCO}$ to the individual hospitals to which they were physically attached. Second, a newly-designed performance agreement between the boards of 11 hospitals and the board of Cancer Care Ontario took effect, linking future funding for cancer services to volume, quality and reporting requirements. Third, CCO began its new future as a radically different organization. By shifting attention away from day-to-day management of cancer centres, CCO would focus on planning, performance improvement and system change on a provincewide basis.

\section{A New Beginning ... But the Jury Is Still Out}

January 1, 2004 was the start of a new era for all of us. CCO and the host hospitals delivered on their joint commitment to make integration happen; and now we have moved into the phase of living with what we created. There is widespread pride in our collective achievement and a sense of ownership over the new system that has emerged. Many people said that it could not be done, and continue to be surprised that the hospitals and CCO actually came as far as we did. Implementation of the new arrangement is going well thus far, but it is too soon, to rest on the laurels of success as there is still much work to do. Not surprisingly, we have already uncovered some challenges that require additional work.

The new accountability agreement identifies ways in which we, as partners, will demonstrate performance within the context of an overall provincial plan. Linking individual hospital performance targets to overall system objectives is a distinctive feature of this agreement. Hospitals will participate with CCO on the development of standards, guidelines and benchmarks for cancer care, and provide data for ongoing tracking and reporting of performance. Annual performance requirements will be set by each hospital and $\mathrm{CCO}$, and include expectations for volume, cost and quality. Quarterly reviews will be in place to track progress, and there are provisions for acting on substantial variances from performance and reporting requirements, funding shortfalls and conflict between the organizations. In response to system need, the ability to move cancer treatment volumes and funding around the province in certain circumstances is an important feature, and all parties have verification and audit capabilities. An additional collaboration agreement between $\mathrm{CCO}$ and Princess Margaret Hospital (PMH) strengthens the integration model even further, by bringing PMH to the table as a full partner with all the other ICPs.

So how will we know if integration efforts have been 
successful? In addition to some local evaluation efforts, CCO is working with the Cancer Quality Council of Ontario to develop a complementary research agenda . This research will examine the degree or extent of integration of cancer services within each of the ICPs, and within their corresponding regions. Measures of integration include assessment of the extent to which patient care services are coordinated across various functions, activities and operating units of a system (clinical), how providers are economically linked to a system, use its facilities and services and actively participate in its planning, management and governance (provider-system), and the extent to which key support functions and activities are coordinated across operating units of a system (functional)(Gillies et al. 1993). With a developed measure of integration, specific to cancer care, we will be able to compare its impact on a range of performance indicators, allowing us to gauge, to some degree, the success of our integration efforts. At the system level, the Cancer Quality Council of Ontario has developed a quality indicator scorecard spanning cancer prevention through to end-of-life care. Starting in early 2005, this scorecard will be used for public reporting of cancer system performance. This tool will enable measurement of cancer system performance before and after integration.

\section{Linking individual hospital perform- ance targets to overall system objectives is a distinctive feature of this agreement.}

To get an early read on how things were going, CCO commissioned a qualitative study to gauge the perspectives of key healthcare stakeholders. It found that there is tremendous excitement regarding the new model and that people are cheering us on - especially with respect to standard-setting and the use of performance agreements. On the other hand, the clear response from study participants was that "the jury is still out." More evidence needs to accumulate to satisfy claims of success, and our partnership still needs to deliver on its potential. Ultimately, the integrated model will be judged on the answer to the question that kept us focused and motivated over the course of the entire progress: Are more patients receiving better cancer care services than they would have under the old system?

\section{IMPLICATIONS FOR THE FUTURE}

On the surface, this whole effort could be viewed as a wellorchestrated devolution of clinical services from one entity to 11 others. We believe the implications of the changes we undertook run much deeper than this, for four reasons.

First, never in the history of Ontario have 12 different organizations come together voluntarily to design and implement a whole new system of care within a 14-month window. The scope and complexity of the change that was undertaken was daunting. It was achieved because of the people involved. There were many talented and dedicated individuals and teams that rose to the occasion in difficult times to make this happen. They were motivated because they knew they were part of something that mattered, and that the leaders were serious about seeing this change through. This is an important leadership precedent for the healthcare system.

The second significant implication is that the entire cancer issue has just been reframed. The fallacy that radiation wait times are the single most important problem to solve will fade as we focus on issues of access to CT scans, cancer surgery and palliative care. Attention to the full continuum of care will unlock our capacity to work together to develop patient-centred networks and other vehicles of change designed to improve quality of care. Too often we box ourselves in by paying attention to issues within the four walls of our institutions and look at only part of the problem. Stepping out of one's traditional territory to work with others on common issues is the only effective way to function.

A third implication relates to shifts in power. $\mathrm{CCO}$ has exchanged its traditional levers of power (derived from provider and line management budget controls) for new accountability tools and an increased sphere of influence. This exchange may look disempowering to some, but in reality it is the complete opposite. By partnering with others across the system to improve the quality of cancer care, everyone becomes stronger and more effective. The relationships we have created through the ICP agreement can be leveraged for other causes. CCO is in a much better position now to deliver value not only to its new hospital partners, but also to government as its sole ministerial advisor on all cancer services. Hospitals are in a better position to deal with the growing demands and burden of cancer in their organizations and within their local communities. The job now is to sustain the positive momentum of change that has been fostered and deliver more results.

The final implication for the future is that a platform for further change has been created.

We are confident that the new partnerships created by CCO, ICP Hospitals and PMH will yield benefits for years to come. Seeing the success of integration, many others are coming on board as well. A major planning exercise for the Greater Toronto Area that looked out to the year 2014 was just completed and 
it brought hospitals, CCACs, DHCs and CCO together in an unprecedented fashion. Now regional cancer plans are being developed across the province and RVPs are playing key leadership roles in their local communities. The Ministry is supporting efforts to design and implement a new multi-year funding strategy for cancer services. This too is a significant breakthrough. CCO will host a provincial cancer summit in September 2005 to look at how the new integrated system is performing and what the next priorities for action should be.

It is exciting to be part of shaping a new era. In our view, the ability to translate ideas into action is the essence of leadership, and it will be the hallmark of our future success. We agree completely with authors Bossidy and Charan who state: "without the ability to execute, all other attributes of leadership become hollow." So stay tuned and watch as we work together again, this time with the resolve to help create the best cancer system in the world. Patients and families are counting on us. IQ

\section{References}

Bossidy, L and R. Charan. 2002. Execution: The Discipline of Getting Things Done. New York: Crown Business Publishers.

Gillies, R.R., S.M. Shortell, D.A. Anderson, J.B. Mitchell and K.L. Morgan. 1993. "Conceptualizing and Measuring Integration: Findings from the Health Systems Integration Study." Hospital and Health Services Administration 38(4): 467-489
Hudson, A.R. 2001. Report of the Cancer Services Implementation Committee. Toronto. Retrieved May 9, 2004. < www.health.gov. on.ca/english/public/pub.ministry_reports/hudson/hudson.pdf>

Hudson, A.R. 2002. "The First 200 Days: Cancer Leadership in Ontario.” Hospital Quarterly 6(1): 30-35.

Sullivan, T., Q. Evans, H. Angus and A. Hudson. 2003. Strengthening the Quality of Cancer Services in Ontario. Ottawa: CHA Press.

\section{About the Authors \\ Leslee J. Thompson is Provincial Vice-President, Cancer System Integration \& Performance at Cancer Care Ontario. She was executive lead for Integration at CCO.}

Mail address: 620 University Avenue, 16th Floor, Toronto, ON M5G 2L7 E-mail: leslee.thompson@cancercare.on.ca

Murray T. Martin is President \& Chief Executive Officer, Hamilton Health Sciences Centre. He was leader of Hospital CEO group during negotiations with CCO.

\section{Acknowledgements}

The authors wish to express their thanks to the hundreds of individuals who helped make integration happen. In particular, thanks goes to Alan R. Hudson, President \& Chief Executive Officer, Cancer Care Ontario for never falling short on his promise to help us do what people said could not be done.

\section{Healthcare relies heavily on immigrants}

The U.S. healthcare system relies heavily upon immigrants to work as clinicians and other skilled healthcare workers, with immigrants currently at $13 \%$ of all healthcare providers. According to a recent study sponsored by the American Immigration Law Foundation, foreign-born workers account for:

- $25.2 \%$ of U.S. physicians,

- $17 \%$ of nursing, psychiatric, and home health aides,

- $15.8 \%$ of clinical laboratory technicians,

- $14.8 \%$ of pharmacists, and

- $11.5 \%$ of registered nurses.

(Source: Modern Healthcare)

Health $P R O$ Procurement Services Inc. Canada's largest and \#1 choice for group purchasing.

Representing healthcare facilities from across the country, we gain the advantage from over $\$ 500$ million in contract volumes.

These volumes translate into significant off-invoice savings for our members' consumable healthcare requirements.

One membership fee gives you access to all programs. Enjoy flexible commitment to contracts in the areas of:

- Clinical

- Pharmacy

- Special Services

For more information about becoming a member and shareholder, contact: Cynthia Valaitis, Business Development Phone: 905-568-3478 X310 E-mail: cvalaitis@ healthpro-ont.com

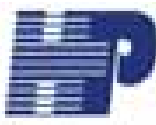

